\title{
Prolonged feeding of difructose anhydride III increases strength and mineral concentrations of the femur in ovariectomized rats
}

\author{
Rieko Mitamura and Hiroshi Hara* \\ Division of Applied Bioscience, Graduate School of Agriculture, Hokkaido University, Kita-9, Nishi-9, Kita-ku, Sapporo 060-8589, Japan \\ (Received 15 December 2004 - Revised 2 March 2005 - Accepted 9 March 2005)
}

\begin{abstract}
This study demonstrates that feeding difructose anhydride III (DFAIII) improves bone strength and femoral mineral concentrations in a rat model of oestrogen deficiency. We showed the relationship between $\mathrm{Ca}, \mathrm{Mg}$ and $\mathrm{P}$ absorption and bone characteristics in rats. Two groups of female Sprague-Dawley rats (6 weeks old) underwent bilateral ovariectomy (ovariectomized rats, OVX rats) or bilateral laparotomy (sham rats). At 10 weeks old, OVX and sham rats were divided into three subgroups and fed a control, $1.5 \%$ DFAIII or $3 \%$ DFAIII diet for 8 weeks, respectively. Ca but not Mg absorption rates were lowered by ovariectomy; however, ingestion of the $1.5 \%$ and $3 \%$ DFAIII diets similarly restored the reduced Ca absorption in OVX rats at 4 and 8 weeks after feeding of the test diets. DFAIII increased Mg absorption dose-dependently in sham and OVX rats. The bone strength, femoral Ca and Mg concentrations, and distal bone mineral density in the $3 \%$ DFAIII group were higher than those in the control group in OVX rats. The absorption rates of Ca and Mg were significantly correlated with femoral $\mathrm{Ca}$ and $\mathrm{Mg}$ concentrations and strength, which suggests that increasing both $\mathrm{Ca}$ and $\mathrm{Mg}$ absorption improves bone characteristics in OVX rats. There were no differences in any of the variables in the femur between the $1.5 \%$ and $3 \%$ DFAIII groups in OVX rats. In conclusion, feeding of a low dose of DFAIII increased intestinal $\mathrm{Ca}$ and $\mathrm{Mg}$ absorption, and the promotive effect of DFAIII persisted for over 8 weeks. This effect was associated with prevention of ovariectomy-induced osteopenia.
\end{abstract}

Difructose anhydride III: Ca absorption: Bone strength: Ovariectomized rats

It is well known that ovarian hormone deficiency is involved in osteoporosis (Kanis, 1996; Qu et al. 2000). Oestrogen replacement therapy has been shown to be effective in preventing bone loss (Kanis, 1996); however, this therapy may induce serious side-effects (Eastell, 2003). There is considerable interest in dietary alternatives that include the consumption of phyto-oestrogen and increasing $\mathrm{Ca}$ intake (Breitman et al. 2003). Some studies have shown that oestrogen deficiency in post-menopausal or oophorectomized women impairs intestinal $\mathrm{Ca}$ absorption and decreases bone mineral density (BMD) (Holzherr et al. 2000; van den Heuvel et al. 2000), and these impairments were demonstrated in ovariectomized (OVX) rats (O'Loughlin \& Morris, 1994; Kalu \& Orhii, 1999; Mitamura et al. 2002). Moreover, $\mathrm{Ca}$ intake in East Asian people including Japanese is lower than the dietary reference intake of Ca (Ministry of Health, Labour and Welfare in Japan, 2002).

Absorption of $\mathrm{Ca}, \mathrm{Mg}$ and $\mathrm{P}$ influences bone composition and structure as they are the main components of bone and contribute to bone strength with changes in bone metabolism (Ilich \& Kerstetter, 2000; Eastell \& Lambert, 2002). Bone collagen also contributes to bone toughness (Oxlund et al. 1995; Wang et al. 2002). $\mathrm{Cu}$ and $\mathrm{Fe}$ are also known to influence maturation of collagen as lysyl oxidase is a $\mathrm{Cu}$-containing enzyme and $\mathrm{Fe}$ is a co-factor for lysyl hydroxylase (Medeiros et al. 1997, 2002). Among these dietary factors, the importance of $\mathrm{Ca}$ intake is well reported for the prevention of osteoporosis. A low $\mathrm{Ca}$ intake increases bone resorption and induces bone loss (Ginty et al. 1998; Talbott et al. 1998). However, a previous study has shown that increasing dietary $\mathrm{Ca}$ intake above the recommended level had no effect on bone mineral composition in rats (Creedon \& Cashman, 2001). Therefore, not only an increase in Ca intake but also improvement in mineral absorption may be necessary to prevent osteoporosis in post-menopausal women.

Several reports have indicated that ingestion of oligosaccharides and fermentable dietary fibres increases Ca absorption in rats (Ohta et al. 1995; Hara et al. 1999; Roberfroid, 1999; Mitamura et al. 2003). Difructose anhydride III (DFAIII) is a newly manufactured non-digestible saccharide prepared from inulin with Arthrobacter sp. H65-7 inulin fructotransferase (Inulinase II; EC 24.1.93). Recently, we have reported that DFAIII promotes Ca absorption in in vivo and in vitro experiments (Suzuki et al. 1998; Mineo et al. 2001, 2002; Mitamura et al. 2002; Shiga et al. 2003; Suzuki \& Hara, 2004). The proposed mechanisms for the promotion of $\mathrm{Ca}$ absorption are reported that intact DFAIII stimulates paracellular Ca absorption in the small intestine (Mineo et al. 2001, 2002; Suzuki \& Hara, 2004) and ingestion of DFAIII increases the SCFA pool and decreases the $\mathrm{pH}$ value of the caecal contents and this fermentation of DFAIII is involved in the increased Ca absorption in the large intestine in OVX rats (Mitamura et al. 2002). Our previous study also showed that feeding DFAIII restored the ovariectomy-induced reduction in $\mathrm{Ca}$ absorption and led to increases in bone strength and femoral Ca content (Mitamura et al. 2002). 
However, the previous study conducted to determine the contribution of the small and large intestine to the promotive effects of DFAIII used caecocolonectomized rats. Therefore, the relationship between DFAIII feeding and the promotion of $\mathrm{Ca}$ absorption and bone characteristics has not been fully elucidated. Also, the 4week feeding period in the previous study was relatively short for the observation of bone metabolism.

The aim of the present study was to clarify the relationship between $\mathrm{Ca}$ absorption and bone characteristics in OVX rats after feeding DFAIII. The rats were fed the stock diet without DFAIII for 4 weeks after ovariectomy to induce Ca malabsorption with oestrogen deficiency, and were then given the test diets for 8 weeks. We then assessed the effects of DFAIII on Ca absorption, and femur variables, such as bone mineral and collagen contents, bone-breaking force, regional BMD, and bone turnover, in both sham and OVX rats. Furthermore, we confirmed the dose-dependent effect of DFAIII.

\section{Materials and methods}

\section{Animals and diets}

Female Sprague-Dawley rats (6 weeks old; Japan Clea, Tokyo, Japan) weighing about $150 \mathrm{~g}$ were housed in individual stainless-steel cages with wire-mesh bottoms. The cages were placed in a room with controlled temperature $\left(22-24^{\circ} \mathrm{C}\right)$, relative humidity $(40-60 \%)$ and lighting (lights on $08.00-20.00$ hours). The rats had free access to deionized water and the stock diet shown in Table 1 for a $4 \mathrm{~d}$ adaptation period.

This study was approved by the Hokkaido University Animal Committee, and the rats were maintained in accordance with the Hokkaido University guidelines for the care and use of laboratory animals.

\section{Study design}

At 6 weeks old, the rats were divided into two groups; rats of one group underwent bilateral ovariectomy (OVX rats) and those of the other group underwent bilateral laparotomy (sham rats). After the operation, all rats were fed the stock diet for 4 weeks. At 10 weeks, the rats in each group were divided into three subgroups of nine or ten rats, and then given one of the test diets (control, $1.5 \%$ DFAIII ( $15 \mathrm{~g} / \mathrm{kg}$ diet) or $3 \%$ DFAIII $(30 \mathrm{~g} / \mathrm{kg}$ diet $))$ shown in Table 1 for 8 weeks. To prevent hyperphagia associated with ovariectomy, the OVX rats were given the average amount of

Table 1. Composition of stock and test diets*

\begin{tabular}{|c|c|}
\hline Component & Amount $(\mathrm{g} / \mathrm{kg})$ \\
\hline Caseint & 250 \\
\hline Maize oil & 50 \\
\hline Mineral mixtureł & 35 \\
\hline Vitamin mixture $\ddagger$ & 10 \\
\hline Choline bitartrate & 2.5 \\
\hline Cellulose§ & 50 \\
\hline Sucrose & To make $1 \mathrm{~kg}$ \\
\hline \multirow{4}{*}{\multicolumn{2}{|c|}{$\begin{array}{l}\text { *Difructose anhydride III ( } 15 \text { or } 30 \mathrm{~g} / \mathrm{kg} \text { diet; Nippon Beet Sugar, Obi- } \\
\text { hiro, Japan) was added to the test diet. } \\
\text { † ALACID; New Zealand Dairy Board, Wellington, New Zealand. } \\
\text { † Mineral and vitamin mixtures were prepared in accordance with the } \\
\text { AIN-93G formulation (Reeves et al. 1993) without Ca. The Ca con- } \\
\text { centration was } 3.0 \mathrm{~g} \mathrm{Ca} / \mathrm{kg} \text { diet. }\end{array}$}} \\
\hline & \\
\hline & \\
\hline & \\
\hline \multicolumn{2}{|c|}{ § AVICEL; Asahi Chemical Industry, Tokyo, Japan. } \\
\hline
\end{tabular}

food ingested by the sham rats each day during the experimental period.

The body weight and food intake were measured each day. Faeces were collected three times; before feeding of the test diet (week 0), from day 23 to day 27 (week 4) or from day 51 to day 55 (week 8) after feeding of the test diets. From day 54, urine was collected for $24 \mathrm{~h}$ to measure deoxypyridinoline (DPD). On the last day, the rats were anaesthetized (Nembutal: sodium pentobarbital, $50 \mathrm{mg} / \mathrm{kg}$ body weight; Abbott Laboratories, North Chicago, IL, USA), then killed by withdrawal of the aortic blood. Both femurs were then removed, carefully cleaned of adherent tissue, and the left femurs were used to measure bone strength. The right femurs were used to measure $\mathrm{BMD}$, the femurs were then freeze-dried to measure mineral and collagen concentrations. The uterus was removed and weighed to confirm the success of the ovariectomy in each rat.

\section{Analytical methods}

Freeze-dried faeces were milled, and the powdered samples $(100 \mathrm{mg})$ were wet-ashed with an acid mixture $(16 \mathrm{~mol} / \mathrm{l}$ $\mathrm{HNO}_{3}: 9$ mol/1 $\mathrm{HClO}_{4} 3: 1$ ) without drying. The amounts of $\mathrm{Ca}$ and $\mathrm{Mg}$ in the right femurs were measured after the samples had been hydrolysed at $110^{\circ} \mathrm{C}$ for $24 \mathrm{~h}$ with $6 \mathrm{~mol} / \mathrm{l} \mathrm{HCl}$. Ca and $\mathrm{Mg}$ concentrations in those solutions were measured by atomic absorption spectrophotometry (AA-6400F; Shimadzu Corporation, Kyoto, Japan) after appropriate dilution with $0.1 \mathrm{~mol} / \mathrm{l}$ $\mathrm{HCl}$. P concentration in the solutions of the ashed faeces and hydolysed femur was determined by the molybdovanadate method (Ueda \& Wada, 1970). Hydroxyproline concentration in the acid hydrolysate of the femur was determined by a colorimetric method (Bergman \& Loxley, 1970) in which the hydrolysed solution was oxidized by chloramine- $\mathrm{T}$ and applied to colorimetry by Ehrlich reaction at $558 \mathrm{~nm}$.

The maximum breaking force of the left femoral diaphysis (the centre of the femur) was measured as the bone strength. A threepoint bending test (Shiga et al. 2002) was performed with a rheometer (RE-3305 Rheoner; Yamaden, Tokyo, Japan) under the following conditions: sample space, $1.0 \mathrm{~cm}$; pranger speed, $30 \mathrm{~mm} / \mathrm{min}$; load range, $20 \mathrm{~kg}$. The whole BMD of the right femur was measured by dual-energy X-ray absorptiometry with a small animal high-resolution scan module (QDR-4500A; Hologic, Bedford, MA, USA). The regional BMD was estimated: $25 \%$ proximal, $50 \%$ middle (midshaft) and $25 \%$ distal in the right femur.

Urinary DPD concentration was assessed by using a commercial kit (Osteolinks DPD; Sumitomo Pharmaceuticals, Osaka, Japan). Urinary creatinine concentration was measured by the Jaffe reaction (Lustgarten \& Wenk, 1972). Values were expressed as nmol $\mathrm{DPD} / \mathrm{mmol}$ creatinine.

\section{Calculations and statistical analyses}

Apparent $\mathrm{Ca}$ absorption rate was calculated with the following equation:

Ca absorption rate $(\%)=100 \times(\mathrm{Ca}$ intake

$$
-\mathrm{Ca} \text { excretion in faeces)/Ca intake. }
$$

Apparent $\mathrm{Mg}$ and $\mathrm{P}$ absorption rates were calculated in the same manner. 
Values shown represent the means with their standard errors. Statistical analyses were performed by two-way ANOVA (treatment $\times$ diet). Duncan's multiple range test (Duncan, 1955) was used to determine whether mean values were significantly different between groups $(P<0 \cdot 05)$. Pearson's correlation coefficients were calculated. All statistical analyses were done using SPSS for Windows, version 11.0 J (SPSS, Chicago, IL, USA).

\section{Results}

\section{Body weight and food intake}

Final body weight was greater in OVX rats than in sham-operated rats, while there were no differences in food intake $(16.8 \mathrm{~g} / \mathrm{d}$, $P=0 \cdot 857, n 58$ ) between groups (Table 2). Body weight gain was also higher in OVX rats than in sham rats. The uterine weights of all OVX rats were much lower than those of the sham rats. There were no differences in final body weight, body weight gain and uterine weight among the three diet subgroups either in sham or OVX rats.

\section{Mineral absorptions}

As the result of two-way ANOVA in each term (0, 4 and 8 weeks), treatment (ovariectomy) influenced $\mathrm{Ca}$ absorption rate before feeding of test diets ( 0 week) and diet influenced the absorption rate after feeding of test diets (4 and 8 weeks) (Fig. 1). By the post hoc test within 4 or 8 weeks, the absorption rates of $\mathrm{Ca}$ were higher in the $1.5 \%$ and $3 \%$ DFAIII groups than those in the control group for both sham and OVX rats except for sham rats fed $1.5 \%$ DFAIII diet at 4 weeks. Moreover, Ca absorption rates in both DFAIII diet groups of OVX rats were very similar to those of the sham DFAIII diet groups, respectively, at 4 and 8 weeks. There were no differences in $\mathrm{Ca}$ absorption rates between the $1.5 \%$ and $3 \%$ DFAIII groups in sham and OVX rats during feeding of the test diets.

The absorption rate of $\mathrm{Mg}$ was not influenced by ovariectomy, but was influenced by diet at 4 and 8 weeks according to the result of two-way ANOVA (Fig. 2). The absorption rates of Mg in the $1.5 \%$ and $3 \%$ DFAIII diet groups were higher than those in the control diet group in both sham and OVX rats at 4 and 8 weeks. The absorption rate of $\mathrm{Mg}$ was higher in the $3 \%$ DFAIII group than in the $1.5 \%$ DFAIII group at 4 weeks and tended to be higher in the $3 \%$ DFAIII group than in the $1.5 \%$ group in both sham and OVX rats at 8 weeks.

Ovariectomy and diet did not influence $\mathrm{P}$ absorption according to the result of two-way ANOVA (Fig. 3). There were no differences in $\mathrm{P}$ absorption rates among groups in all periods; however, the $\mathrm{P}$ absorption rate was decreased by ageing (week $0,78.8 \%$; week $4,72.1 \%$; week $8,69.2 \% ; P<0.001, n$ 174) according to the result of three-way ANOVA.

\section{Bone strength and mineral status}

The maximum breaking force of the femur was influenced by ovariectomy and diet according to the result of two-way ANOVA (Fig. 4). The values in the control group, but not in either of the DFAIII groups, were lower in OVX rats than in sham rats. In the OVX rats, the maximum breaking force was higher in rats fed the $1.5 \%$ or $3 \%$ DFAIII diet than that in rats fed the control diet. There were no differences in bone strength between the $1.5 \%$ and $3 \%$ DFAIII groups in OVX rats.

The BMD of the whole, proximal and distal femur evaluated by dual-energy X-ray absorptiometry was influenced by ovariectomy treatment, and distal BMD was influenced by diet according to the result of two-way ANOVA (Fig. 5). In OVX rats, distal BMD was higher in the $3 \%$ DFAIII group and tended to be higher in the $1.5 \%$ DFAIII group than in the control group. There were no differences in the midshaft BMD among the groups.

The hydroxyproline concentration of the femur was influenced by ovariectomy, and $\mathrm{Ca}, \mathrm{Mg}$ and hydroxyproline concentrations were influenced by diet according to the result of two-way ANOVA (Table 3). The femoral $\mathrm{Ca}$ and $\mathrm{Mg}$ concentrations were higher in both the DFAIII groups than those in the control group in OVX rats. In sham rats, the femoral Ca concentrations changed in a similar manner without significant differences. The Mg concentration in the $3 \%$ DFAIII group was higher than that in the control diet group in sham rats. The hydroxyproline concentrations in the $3 \%$ DFAIII groups were higher compared

Table 2. Final body weight $(\mathrm{g})$, body weight gain $(\mathrm{g} / \mathrm{d})$ and uterine weight ( $\mathrm{mg} / 100 \mathrm{~g}$ of body weight) of sham and ovariectomized (OVX) rats fed the control or difructose anhydride III (DFAIII) diet for 8 weeks*

(Mean values with their standard errors for nine or ten rats per group)

\begin{tabular}{|c|c|c|c|c|c|c|}
\hline \multirow[b]{2}{*}{ Diet } & \multicolumn{2}{|c|}{ Final body weight } & \multicolumn{2}{|c|}{ Body weight gain } & \multicolumn{2}{|c|}{ Uterine weight } \\
\hline & Mean & SE & Mean & SE & Mean & SE \\
\hline \multicolumn{7}{|l|}{ Sham } \\
\hline Control & $320^{b}$ & $7 \cdot 4$ & $1 \cdot 2^{b}$ & 0.11 & $217^{a}$ & $18 \cdot 1$ \\
\hline $1.5 \%$ DFAIII & $314^{\mathrm{b}}$ & $9 \cdot 3$ & $1 \cdot 1^{\mathrm{b}}$ & 0.09 & $200^{a}$ & $20 \cdot 8$ \\
\hline $3 \%$ DFAIII & $312^{b}$ & $7 \cdot 3$ & $1 \cdot 1^{b}$ & 0.09 & $195^{\mathrm{a}}$ & $13 \cdot 6$ \\
\hline \multicolumn{7}{|l|}{ ovX } \\
\hline Control & $359^{a}$ & $8 \cdot 8$ & $1 \cdot 7^{\mathrm{a}}$ & 0.12 & $27 \cdot 0^{\mathrm{b}}$ & $1 \cdot 18$ \\
\hline $1.5 \%$ DFAIII & $371^{\mathrm{a}}$ & 4.9 & $1.9^{a}$ & 0.07 & $25 \cdot 2^{b}$ & 1.09 \\
\hline $3 \%$ DFAIII & $356^{a}$ & $10 \cdot 4$ & $1 \cdot 6^{\mathrm{a}}$ & 0.12 & $27 \cdot 5^{\mathrm{b}}$ & 1.04 \\
\hline \multicolumn{7}{|c|}{ Significant effects as determined by two-way ANOVA } \\
\hline Treatment $(\mathrm{T})$ & $P<0.001$ & & $P<0.001$ & & $P<0.001$ & \\
\hline Diet (D) & 0.553 & & 0.27 & & 0.618 & \\
\hline$T \times D$ & 0.496 & & 0.286 & & 0.628 & \\
\hline
\end{tabular}

${ }^{a, b}$ Mean values within a column with unlike superscript letters were significantly different $(P<0.05)$.

${ }^{*}$ For details of diets and procedures, see Table 1 and p. 268. 


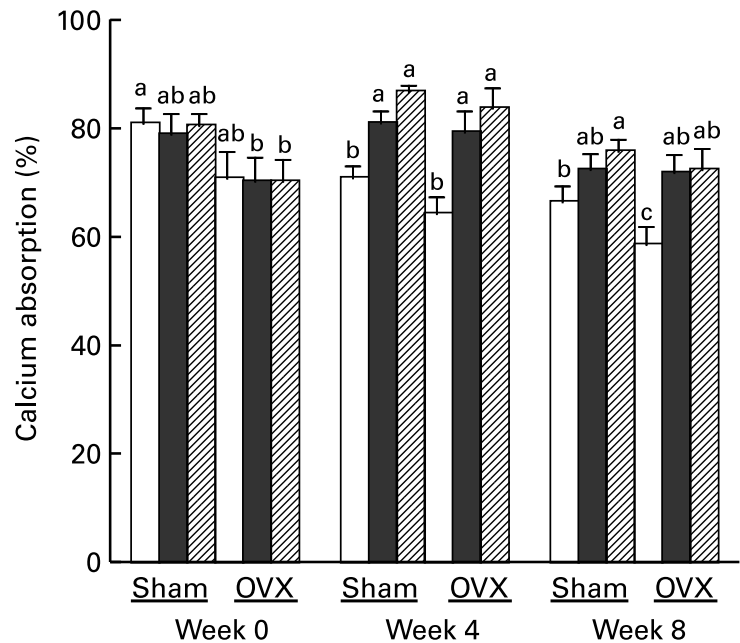

Fig. 1. Calcium absorption rates in sham and ovariectomized (OVX) rats fed


and 8 weeks after starting the test diets. For details of diets and procedures, see Table 1 and p. 268. Values are means with their standard errors for nine or ten rats. $P$ values estimated by two-way ANOVA were $<0.001$ (week 0 ), 0.086 (week 4), 0.049 (week 8) for treatment; 0.922 (week 0), <0.001 (weeks 4 and 8) for diet; and 0.964 (week 0), 0.641 (week 4), 0.374 (week 8) for treatment $\times$ diet. ${ }^{\mathrm{a}, \mathrm{b}, \mathrm{c}}$ Mean values with unlike superscript letters were significantly different $(P<0.05)$.

with those in the control groups in both sham and OVX rats. There were no differences in the femoral dry weight and $\mathrm{P}$ concentrations among groups.

\section{Bone resorption marker}

Urinary DPD levels were influenced by ovariectomy, but not by diet according to the result of two-way ANOVA (Fig. 6). In the

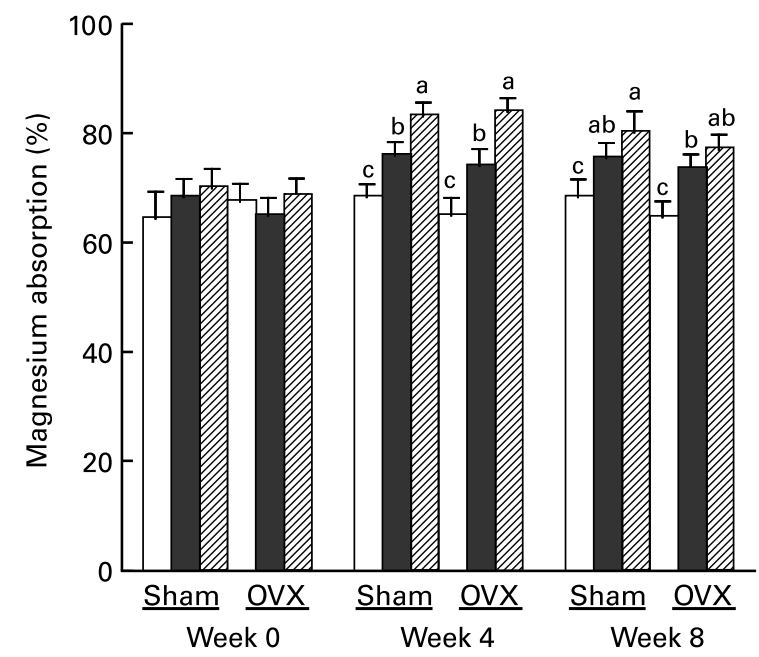

Fig. 2. Magnesium absorption rates in sham and ovariectomized (OVX) rats

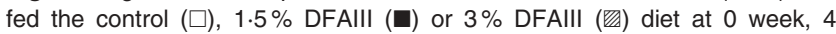
weeks and 8 weeks after starting the test diets. For details of diets and procedures, see Table 1 and p. 268. Values are means with their standard errors for nine or ten rats. $P$ values estimated by two-way ANOVA were 0.855 (week 0), 0.277 (week 4), 0.055 (week 8) for treatment; 0.323 (week 0 ), <0.001 (week 4 and 8) for diet; and 0.443 (week 0), 0.463 (week 4), 0.882 (week 8 ) for treatment $\times$ diet. $^{a, b, c}$ Mean values with unlike superscript letters were significantly different $(P<0.05)$.

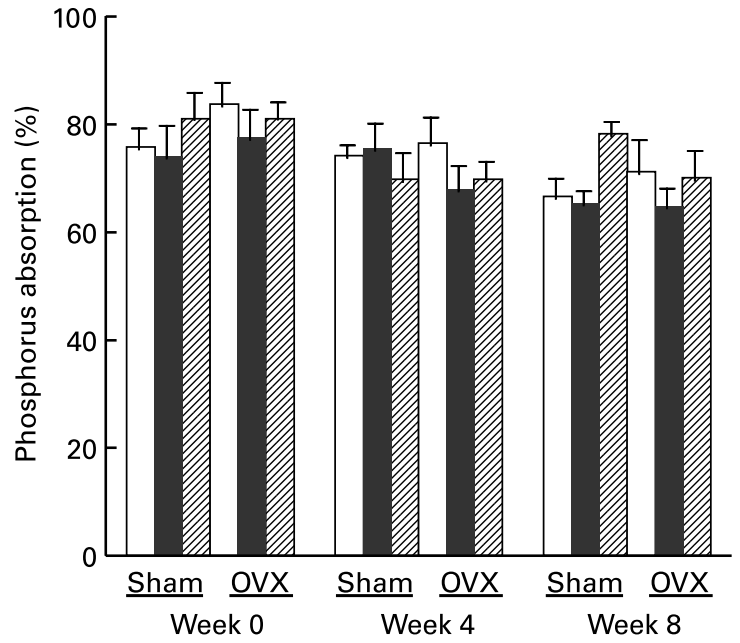

Fig. 3. Phosphorus absorption rates in sham and ovariectomized (OVX) rats

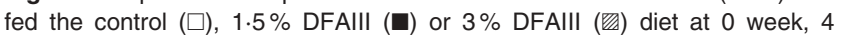
weeks and 8 weeks after starting the test diets. For details of diets and procedures, see Table 1 and p. 268. Values are means with their standard errors for nine or ten rats. $P$ values estimated by two-way ANOVA were 0.285 (week 0), 0.601 (week 4), 0.648 (week 8) for treatment; 0.431 (week 0), 0.369 (week 4), 0.081 (week 8) for diet; and 0.653 (week 0), 0.438 (week 4), 0.253 (week 8 ) for treatment $\times$ diet.

OVX rats, DPD levels in both the DFAIII groups tended to be lower than those in the control group.

\section{Correlation}

Femoral strength was positively correlated with $\mathrm{Ca}$ and $\mathrm{Mg}$ absorption and with femoral $\mathrm{Ca}, \mathrm{Mg}$ and collagen concentrations (Table 4). Femoral strength was also positively correlated with the BMD of all femur segments. The absorption of $\mathrm{Ca}$ was

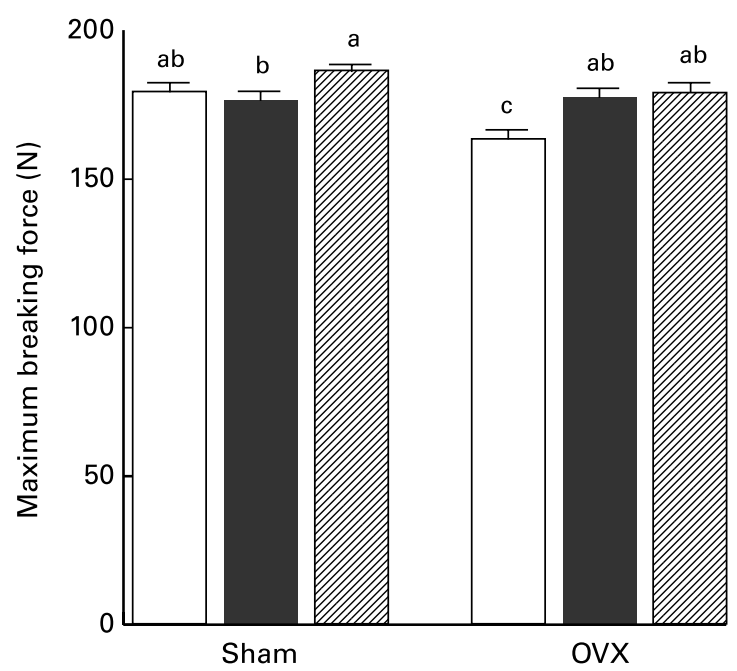

Fig. 4. Maximum breaking force of the femur in sham and ovariectomized

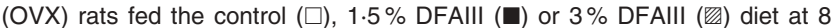
weeks after starting the test diets. For details of diets and procedures, see Table 1 and p. 268. Values are means with their standard errors for nine or ten rats. $P$ values estimated by two-way ANOVA were 0.003 for treatment, 0.001 for diet and 0.020 for treatment $\times$ diet. ${ }^{a, b, c}$ Mean values with unlike superscript letters were significantly different $(P<0.05)$. 


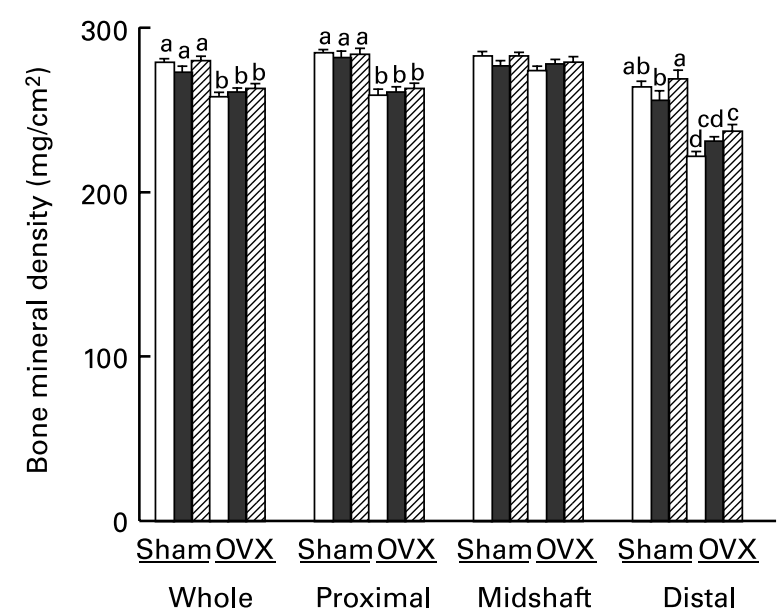

Fig. 5. Femoral bone mineral density of the whole femur and the proximal, midshaft and distal segments of the femur in sham and ovariectomized

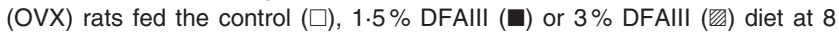
weeks after starting the test diets. For details of diets and procedures, see Table 1 and p. 268. Values are means with their standard errors for nine or ten rats. $P$ values estimated by two-way ANOVA were $<0.001$ (whole, proximal and distal), 0.074 (midshaft) for treatment; 0.314 (whole), 0.751 (proximal), 0.425 (midshaft), 0.040 (distal) for diet; and 0.259 (whole), 0.681 (proximal), 0.233 (midshaft), 0.089 (distal) for treatment $\times$ diet. ${ }^{a, b, c, d}$ Mean values with unlike superscript letters were significantly different $(P<0.05)$.

strongly correlated with BMD, especially distal BMD, and $\mathrm{Mg}$ absorption correlated with only distal BMD. There were no correlations between $\mathrm{P}$ absorption and femoral strength or BMD.

\section{Discussion}

This study is the first report that the prolonged feeding of a nondigestible disaccharide, DFAIII, improves bone characteristics in OVX rats. We clearly demonstrated that 8 weeks of feeding of DFAIII increased femur Ca concentrations and strength in OVX rats (Table 3; Fig. 4), and the increase was associated with the enhancement of intestinal Ca absorption (Fig. 1). We previously demonstrated that DFAIII increases $\mathrm{Ca}$ absorption in both the small and large intestine (Suzuki et al. 1998; Mineo et al.
2001, 2002; Mitamura et al. 2002; Suzuki \& Hara, 2004). To clarify the relationship between $\mathrm{Ca}$ absorption and bone characteristics, we calculated the correlations between mineral absorptions and bone parameter variables and observed positive correlations between $\mathrm{Ca}$ absorption rate and strength, BMD and $\mathrm{Ca}$ concentration of the femur (Table 4). These correlations indicate that an enhancement of $\mathrm{Ca}$ absorption with prolonged feeding of DFAIII may cause an increase in Ca concentration, BMD and bone strength. Ovarian hormone deficiency is well known to be involved in osteoporosis (Kanis, 1996; Qu et al. 2000) and an adequate supply of $\mathrm{Ca}$ with improvement in $\mathrm{Ca}$ absorption by DFAIII may prevent bone loss in post-menopausal women.

The present study showed that feeding of DFAIII increased Ca absorption over 8 weeks, which is the longest feeding period in experiments on DFAIII in rats. We used a $3.0 \mathrm{~g} \mathrm{Ca} / \mathrm{kg}$ diet level that is lower than the level of the standard diet in rats, AIN93G, which simulates a lower Ca intake than the dietary reference intake of $\mathrm{Ca}$ in East Asia including Japan (Ministry of Health, Labour and Welfare in Japan, 2002). We showed that rather high absorptive rates of $\mathrm{Ca}$ were maintained with feeding DFAIII over 8 weeks in OVX and also sham rats. The prolonged effects of DFAIII on Ca absorption and bone suggest a potential benefit to post-menopausal women with lower $\mathrm{Ca}$ intake. Moreover, the $\mathrm{Ca}$ content of the kidney did not differ among groups (data not shown), which suggests that feeding of DFAIII does not induce any renal side-effects even with prolonged increases in $\mathrm{Ca}$ absorption.

$\mathrm{Mg}$ is also an important factor for bone strength, though the content is low in the bone $(0 \cdot 5-1 \%$ bone ash). Mg deficiency impairs bone growth and causes skeletal fragility (Rude et al. 2004) and several reports have shown that Mg homeostasis has a great influence on bone strength (Toba et al. 2000; Okuma, 2001). In the present study, $\mathrm{Mg}$ absorption was not influenced by ovariectomy (Fig. 2). However, the rate of $\mathrm{Mg}$ absorption in the DFAIII groups was higher than that in the control groups in both sham and OVX rats. The Mg absorption rate was also correlated with femur strength and $\mathrm{Mg}$ concentration (Table 4). These correlations indicate that an enhancement of $\mathrm{Mg}$ absorption by DFAIII may increase femoral $\mathrm{Mg}$ and may also promote bone strength in OVX rats. In this study, there were no differences in

Table 3. Femoral weight (mg), calcium (mmol/g femur), magnesium ( $\mu \mathrm{mol} / \mathrm{g}$ femur), phosphate (mmol/g femur) and hydroxyproline ( $\mu \mathrm{mol} / \mathrm{g}$ femur) concentration of sham and ovariectomized (OVX) rats fed the control or difructose anhydride III (DFAIII) diet for 8 weeks ${ }^{*}$ (Mean values with their standard errors for nine or ten rats per group)

\begin{tabular}{|c|c|c|c|c|c|c|c|c|c|c|}
\hline Diet & Mean & SE & Mean & SE & Mean & SE & Mean & SE & Mean & SE \\
\hline \multicolumn{11}{|l|}{ Sham } \\
\hline Control & 0.515 & 0.006 & $7 \cdot 11^{\mathrm{ab}}$ & 0.109 & $236^{b c}$ & $7 \cdot 36$ & 3.84 & 0.206 & $166^{\mathrm{b}}$ & 7.89 \\
\hline $1.5 \%$ DFAIII & 0.497 & 0.008 & $7 \cdot 68^{a}$ & 0.065 & $263^{a b}$ & 8.97 & 3.62 & 0.045 & $164^{\mathrm{bc}}$ & $5 \cdot 36$ \\
\hline $3 \%$ DFAIII & 0.506 & 0.012 & $7 \cdot 83^{a}$ & 0.140 & $281^{a}$ & $8 \cdot 60$ & 3.91 & 0.180 & $188^{a}$ & $8 \cdot 30$ \\
\hline $1.5 \%$ DFAIII & 0.510 & 0.019 & $7 \cdot 83^{a}$ & 0.329 & $269^{a b}$ & 14.6 & 3.90 & 0.222 & $156^{\mathrm{bc}}$ & 7.65 \\
\hline $3 \%$ DFAIII & 0.505 & 0.014 & $7 \cdot 58^{a}$ & 0.302 & $259^{a b}$ & $12 \cdot 4$ & 4.00 & 0.161 & $171^{a b}$ & $2 \cdot 88$ \\
\hline \multicolumn{11}{|c|}{ Significant effects as determined by two-way ANOVA } \\
\hline Treatment $(\mathrm{T})$ & 0.789 & & 0.227 & & 0.184 & & 0.986 & & 0.005 & \\
\hline Diet (D) & 0.723 & & $P<0.001$ & & $P<0.001$ & & 0.213 & & $P<0.001$ & \\
\hline
\end{tabular}

a,b,c Mean values within a column with unlike superscript letters were significantly different $(P<0.05)$

${ }^{*}$ For details of diets and procedures, see Table 1 and p. 268. 


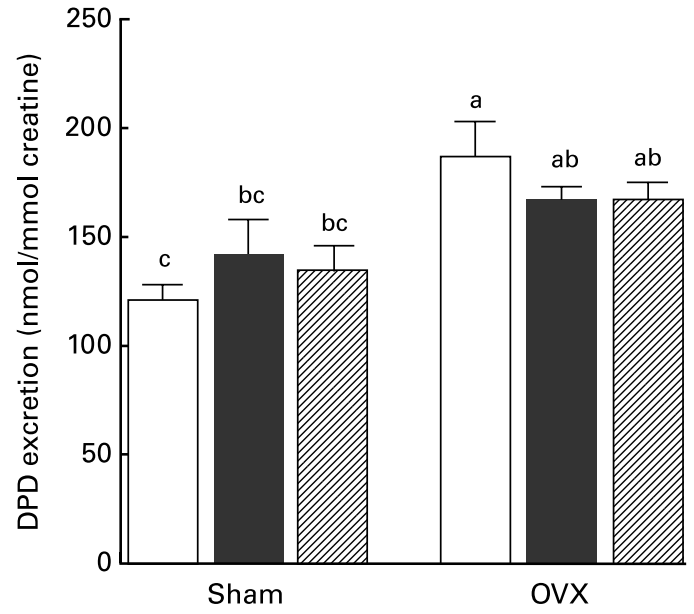

Fig. 6. Urinary deoxypyridinoline (DPD) excretion of sham and ovari-

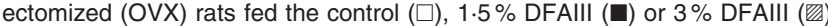
diet at 8 weeks after starting the test diets. For details of diets and procedures, see Table 1 and p. 268. Values are means with their standard errors for nine or ten rats. $P$ values estimated by two-way ANOVA were $<0.001$ for treatment, 0.912 for diet and 0.207 for treatment $\times$ diet. ${ }^{a, b, c}$ Mean values with unlike superscript letters were significantly different $(P<0.05)$.

P absorption rate between groups (Fig. 3). Further, diet did not influence femoral $\mathrm{P}$ concentrations and there were no correlations with any bone parameter variables (Tables 3 and 4). These results showed that DFAIII does not influence $\mathrm{P}$ absorption, and that the absorption of $\mathrm{P}$ has little influence on bone metabolism.

Ovariectomy reduced BMD in the whole, proximal and distal segments of the femur, and feeding of a $3 \%$ DFAIII diet increased BMD only in the distal region of the femur, in which trabecular bone is predominant compared with the midshaft area (Fig. 5). Trabecular bone is more metabolically active than cortical bone (Breitman et al. 2003). In this study, the absorption rates of $\mathrm{Ca}$ and $\mathrm{Mg}$ were positively correlated with distal BMD. These results indicate that the enhancement of $\mathrm{Ca}$ and $\mathrm{Mg}$ absorption by DFAIII improved the trabecular bone area of the femur. The proximal region of the femur also contains trabecular bone. However, DFAIII did not augment BMD of this region. We found that the distal region was lower BMD compared with the other regions especially in OVX rats. This suggests that BMD in the distal femur is more sensitively influenced by ovariectomy, and increasing mineral absorption feeding with DFAIII.

In the present study, we also demonstrated that ingestion of $3 \%$ DFAIII diet, but not $1.5 \%$ DFAIII diet, prevented loss of hydroxyproline (collagen) concentration in OVX rats (Table 3). It has been reported that minerals contribute to bone stiffness and collagen determines the toughness of bone (Oxlund et al. 1995; Wang et al. 2002). The femoral $\mathrm{Ca}, \mathrm{Mg}$ and collagen concentrations were strongly correlated with the maximum breaking force of the femur (Table 4). Preventing bone collagen loss together with increasing bone minerals by ingesting DFAIII may effectively increase bone strength. However, in the case of the $1.5 \%$ DFAIII group in OVX rats, bone strength was increased without prevention of collagen loss. The effect of DFAIII on collagen metabolism is not known. Further studies are needed to clarify the effects of DFAIII ingestion on bone strength and bone architecture and the possibility to improve bone metabolism independent of effects on mineral absorption.

Ovariectomy has been shown to induce osteopenia with an increase in bone turnover dominating bone resorption (Kaastad et al. 1997; Geng et al. 2000). Enhancement of bone resorption results in increases in collagen degradation products (Swaminathan, 2001). We measured urinary excretion of bone resorption marker, the collagen breakdown product DPD. Feeding of DFAIII tended to suppress urinary DPD excretion (Fig. 6); however, excretion was still higher than that in the sham control group and there was no difference between the 1.5 and $3 \%$ DFAIII groups in OVX rats. The $\mathrm{Ca}$ concentrations in the femur of OVX rats fed DFAIII were comparable with those of the sham rats (Table 3). Also, as mentioned earlier, hydroxyproline (collagen) concentration in the $3 \%$ DFAIII group was clearly higher than in the control group, and tended to be higher than in the $1.5 \%$ DFAIII group. These results suggest that the effect of increased $\mathrm{Ca}$ absorption due to the DFAIII diet may more effectively promote bone formation with increasing collagen synthesis than suppression of bone resorption. In this study, we did not measure any bone formation marker. Further studies are required to examine the preventive effects of DFAIII on osteopenia.

We found that there were no differences in $\mathrm{Ca}$ absorption rate or bone variables between the $1.5 \%$ and $3 \%$ DFAIII groups in OVX rats in this study. In the previous studies, effective levels of other non-digestible saccharides in diets were $50-55 \mathrm{~g} / \mathrm{kg}$ diet for the promotion of $\mathrm{Ca}$ absorption in rats (Ohta et al. 1995; Hara et al. 1999; Mitamura et al. 2003; Zafar et al. 2004), which is a much higher level than the effective level of DFAIII. These results demonstrated that a relatively low level of DFAIII in the diet $(15 \mathrm{~g}$ DFAIII $/ \mathrm{kg}$ diet) is sufficient to improve $\mathrm{Ca}$ absorption and bone metabolism.

Table 4. Correlations $(r)$ between mineral absorptions and bone parameter variables in sham and ovariectomized rats fed the control or difructose anhydride III diet for 8 weeks

\begin{tabular}{lcccc}
\hline & Ca absorption & Mg absorption & $\mathrm{P}$ absorption & Femoral strength \\
\hline Femoral strength & $0.468^{\star *}$ & $0.450^{\star *}$ & 0.081 & - \\
Femoral Ca & $0.306^{*}$ & - & - & $0.525^{\star *}$ \\
Femoral Mg & - & $0.536^{\star *}$ & - & $0.489^{\star *}$ \\
Femoral P & - & - & 0.167 & 0.117 \\
Femoral collagen & - & - & - & $0.346^{\star *}$ \\
Bone mineral density & & 0.253 & 0.099 & $0.510^{\star *}$ \\
Whole & $0.352^{* *}$ & 0.243 & 0.093 & $0.433^{\star *}$ \\
Proximal & $0.305^{\star}$ & 0.207 & 0.007 & $0.488^{\star *}$ \\
Midshaft & $0.316^{*}$ & $0.400^{\star *}$ & 0.064 & $0.555^{\star *}$ \\
Distal & $0.459^{\star *}$ & & & \\
\hline
\end{tabular}

${ }^{*, \star \star}$ Significant correlation $\left(n 58,{ }^{*} P<0.05,{ }^{\star \star} P<0.01\right)$. 
In conclusion, prolonged feeding of a low level of DFAIII increased concentrations of bone minerals and collagen, and completely restored bone strength impaired by ovariectomy. We suggest that the enhancement of $\mathrm{Ca}$ and $\mathrm{Mg}$ absorption by DFAIII is involved in these beneficial effects.

\section{References}

Bergman I \& Loxley R (1970) The determination of hydroxyproline in urine hydrolysates. Clin Chim Acta 27, 347-349.

Breitman PL, Fonseca D, Cheung AM \& Ward WE (2003) Isoflavones with supplemental calcium provide greater protection against the loss of bone mass and strength after ovariectomy compared to isoflavones alone. Bone 33, 597-605.

Creedon A \& Cashman KD (2001) The effect of calcium intake on bone composition and bone resorption in the young growing rat. Br J Nutr 86, $453-459$.

Duncan DB (1955) Multiple range and multiple F test. Biometrics 11, $1-42$.

Eastell R (2003) Management of osteoporosis due to ovarian failure. Med Pediatr Oncol 41, 222-227.

Eastell R \& Lambert H (2002) Diet and healthy bones. Calcif Tissue Int 70, 400-404.

Geng W, DeMoss DL \& Wright GL (2000) Effect of calcium stress on the skeleton mass of intact and ovariectomized rats. Life Sci 66, $2309-2321$.

Ginty F, Flynn A \& Cashman K (1998) The effect of short-term calcium supplementation on biochemical markers of bone metabolism in healthy young adults. Br J Nutr 80, 437-443.

Hara H, Suzuki T, Kasai T, Aoyama Y \& Ohta A (1999) Ingestion of guar gum hydrolysate, a soluble fiber, increases calcium absorption in totally gastrectomized rats. J Nutr 129, 39-45.

Holzherr ML, Retallack RW, Gutteridge DH, et al. (2000) Calcium absorption in postmenopausal osteoporosis: benefit of HRT plus calcitriol, but not HRT alone, in both malabsorbers and normal absorbers. Osteoporos Int 11, 43-51.

Ilich JZ \& Kerstetter JE (2000) Nutrition in bone health revisited: a story beyond calcium. J Am Coll Nutr 19, 715-737.

Kaastad TS, Reikeras O, Madsen JE, Narum S, Stromme JH, Obrant KJ \& Nordsletten L (1997) Effects of clodronate on cortical and trabecular bone in ovariectomized rats on a low calcium diet. Calcif Tissue Int 61, 158-164

Kalu DN \& Orhii PB (1999) Calcium absorption and bone loss in ovariectomized rats fed varying levels of dietary calcium. Calcif Tissue Int 65, 73-77.

Kanis JA (1996) Estrogens, the menopause, and osteoporosis. Bone 19, 185S-190S.

Lustgarten JA \& Wenk RE (1972) Simple, rapid, kinetic method for serum creatinine measurement. Clin Chem 18, 1419-1422.

Medeiros DM, Ilich J, Ireton J, Matkovic V, Shiry L \& Wildman R (1997) Femurs from rats fed diets deficient in copper or iron have decreased mechanical strength and altered mineral composition. J Trace Elem Exp Med 10, 197-203.

Medeiros DM, Plattner A, Jennings D \& Stoecker B (2002) Bone morphology, strength and density are compromised in iron-deficient rats and exacerbated by calcium restriction. J Nutr 132, 3135-3141.

Mineo H, Hara H, Kikuchi H, Sakurai H \& Tomita F (2001) Various indigestible saccharides enhance net calcium transport from the epithelium of the small and large intestine of rats in vitro. J Nutr 131, 3243-3246.

Mineo H, Hara H, Shigematsu N, Okuhara Y \& Tomita F (2002) Melibiose, difructose anhydride III and difructose anhydride IV enhance net calcium absorption in rat small and large intestinal epithelium by increasing the passage of tight junctions in vitro. J Nutr 132, 3394-3399.

Ministry of Health, Labour and Welfare in Japan (2002) National Nutrition Survey 2000. Tokyo: Daiichi-shuppan.
Mitamura R, Hara H, Aoyama Y \& Chiji H (2002) Supplemental feeding of difructose anhydride III restores calcium absorption impaired by ovariectomy in rats. J Nutr 132, 3387-3393.

Mitamura R, Hara H, Aoyama Y, Takahashi T \& Furuta H (2003) Ingestion of water-soluble soybean fiber prevents osteopenia and hypercholesterolemia induced by ovariectomy in rats. J Agric Food Chem 51, $1085-1089$.

Ohta A, Ohtsuki M, Baba S, Adachi T, Sakata T \& Sakaguchi E (1995) Calcium and magnesium absorption from the colon and rectum are increased in rats fed fructooligosaccharides. J Nutr 125, 2417-2424.

Okuma T (2001) Magnesium and bone strength. Nutrition 17, 679-680.

O'Loughlin PD \& Morris HA (1994) Oophorectomy in young rats impairs calcium balance by increasing intestinal calcium secretion. $J$ Nutr 124, $726-731$.

Oxlund H, Barckman M, Ortoft G \& Andreassen TT (1995) Reduced concentrations of collagen cross-links are associated with reduced strength of bone. Bone 17, 365S-371S.

Qu Q, Zheng H, Dahllund J, et al. (2000) Selective estrogenic effects of a novel triphenylethylene compound, FC1271a, on bone, cholesterol level, and reproductive tissues in intact and ovariectomized rats. Endocrinology 141, 809-820.

Reeves PG, Nielsen FH \& Fahey GC Jr (1993) AIN-93 purified diets for laboratory rodents: final report of the American Institute of Nutrition ad hoc writing committee on the reformulation of the AIN-76A rodent diet. J Nutr 123, 1939-1951.

Roberfroid MB (1999) Concepts in functional foods: the case of inulin and oligofructose. J Nutr 129, 1398S-1401S.

Rude RK, Gruber HE, Norton HJ, Wei LY, Frausto A \& Mills BG (2004) Bone loss induced by dietary magnesium reduction to $10 \%$ of the nutrient requirement in rats is associated with increased release of substance $\mathrm{P}$ and tumor necrosis factor. $J$ Nutr $\mathbf{1 3 4}, 79-85$.

Shiga K, Hara H, Okano G, Ito M, Minami A \& Tomita F (2003) Ingestion of difructose anhydride III and voluntary running exercise independently increase femoral and tibial bone mineral density and bone strength with increasing calcium absorption in rats. $J$ Nutr 133, $4207-4211$.

Shiga K, Hara H, Takahashi T, Aoyama Y, Furuta H \& Maeda H (2002) Ingestion of water-soluble soybean fiber improves gastrectomy-induced calcium malabsorption and osteopenia in rats. Nutrition 18, 636-642.

Suzuki T \& Hara H (2004) Various non-digestible saccharides increase intracellular calcium ion concentration in rat small-intestinal enterocytes. Br J Nutr 92, 751-755.

Suzuki T, Hara H, Kasai T \& Tomita F (1998) Effects of difructose anhydride III on calcium absorption in small and large intestines of rats. Biosci Biotechnol Biochem 62, 837-841.

Swaminathan R (2001) Biochemical markers of bone turnover. Clin Chim Acta 313, 95-105.

Talbott SM, Rothkopf MM \& Shapses SA (1998) Dietary restriction of energy and calcium alters bone turnover and density in younger and older female rats. J Nutr 128, 640-645.

Toba Y, Kajita Y, Masuyama R, Takada Y, Suzuki K \& Aoe S (2000) Dietary magnesium supplementation affects bone metabolism and dynamic strength of bone in ovariectomized rats. J Nutr 130, $216-220$.

Ueda I \& Wada T (1970) Determination of inorganic phosphate by the molybdovanadate method in the presence of ATP and some interfering organic bases. Anal Biochem 37, 169-174.

van den Heuvel EG, Schoterman MH \& Muijs T (2000) Transgalactooligosaccharides stimulate calcium absorption in postmenopausal women. J Nutr 130, 2938-2942.

Wang X, Shen X, Li X \& Agrawal CM (2002) Age-related changes in the collagen network and toughness of bone. Bone 31, 1-7.

Zafar TA, Weaver CM, Zhao Y, Martin BR \& Wastney ME (2004) Nondigestible oligosaccharides increase calcium absorption and suppress bone resorption in ovariectomized rats. J Nutr 134, 399-402. 